\title{
TRANSPORT IMPACTS OF THE COPENHAGEN METRO
}

\author{
Jane Ildensborg-Hansen \\ TetraPlan A/S, Copenhagen, Denmark (jih@tetraplan.dk) \\ Goran Vuk \\ Danish Transport Research Institute, Lyngby, Denmark, (gv@dtf.dk)
}

\begin{abstract}
A large scale research project has followed the opening of the Copenhagen metro's phase 1 and phase $2 a$ where the focus was to analyse the changes in travel behaviour. A long list of transport impacts was identified and quantified in the project, all of them depended on a geographical location and the time the changes were measured relative to the before-metro situation.

Due to the metro, we have experienced a general growth in public transport over the years after metro's opening; an experience which is rather opposite of what we were used to. A major part of that increase is related to the newly generated traffic, i.e. induced traffic. Most of the new metro traffic happens in day periods out of the two peaks, especially in the evening, resulting in changes in the proportion of traffic in different day time periods, i.e. the peaks are less extreme in the after-metro situation.

Finally, the metro has influenced changes in modal split, where the existing public transport modes, i.e. bus and S-train, lost large portions of their before-metro traffic to the metro. It was interesting to notice that in highly populated areas of Copenhagen, e.g. Frederiksberg, the metro had a large impact in shift from car to public transport.
\end{abstract}

\section{INTRODUCTION}

The Copenhagen metro is the main improvement made to Denmark's urban public transport infrastructure in the last decade. Important arguments in favour of a new public transport system in the capital were to increase market share for public transport, thus reducing car traffic, and enhancing urban development, especially on the island of Amager, whose only previous link to the city was bus service.

The focus of this article is an evaluation of transport impacts of the Copenhagen metro on traffic growth, induced traffic and choice of mode and destination. The effects were measured in two parts of the capital; an area called Frederiksberg and the corridor between islands Sjælland and Amager, so called Harbour corridor, in relation to the metro's phases 1 , $2 \mathrm{a}$ and $2 \mathrm{~b}$.

The whole complex of analysis and results of the metro impact study is published as a report from the Danish Transport Research Institute (Vuk and Ildensborg-Hansen, 2006).

Furthermore the main results have been published in Journal of Transport Geography (Vuk, 2005).

\section{METRO IN COPENHAGEN}

Already in 1961, there were plans to build an S-train connection between the islands of Sjælland and Amager, on which Copenhagen is located (Steen Eiler Rasmussen, 2001). The alignment was a straight line between west Amager and the city. At that time, west Amager 
was unpopulated, and the plans proposed building some 40,000 new dwellings to ease the pressure on the fast-growing city centre.

In 1992, the Danish Parliament passed the Ørestad Act permitting the construction of a new railway infrastructure in Copenhagen. The government thus endorsed the regeneration of public transport and the reduction of road congestion in the Danish capital. Of the three suggested public transport modes - metro, light rail and tram - the first option was chosen. Metro construction started in 1994 and the first phase was opened on $19^{\text {th }}$ October 2002. The construction costs of phase 1 of the metro amounted to DKK 6.7 billion (approximately EUR 900 million). Figure 1 shows the metro's alignment. The 11-km route consists of two metro lines connecting the island of Amager in the south with the city terminus at Nørreport on the island of Sjælland. Metro line 1 (M1) runs to a new town Ørestad in west Amager while metro line 2 (M2) runs to Lergravsparken in east Amager. The two lines meet on the Amager side of the harbour corridor, just before Knippelsbro bridge where the line goes underground.

Figure 1. Alignment of the M1 and M2 metro lines

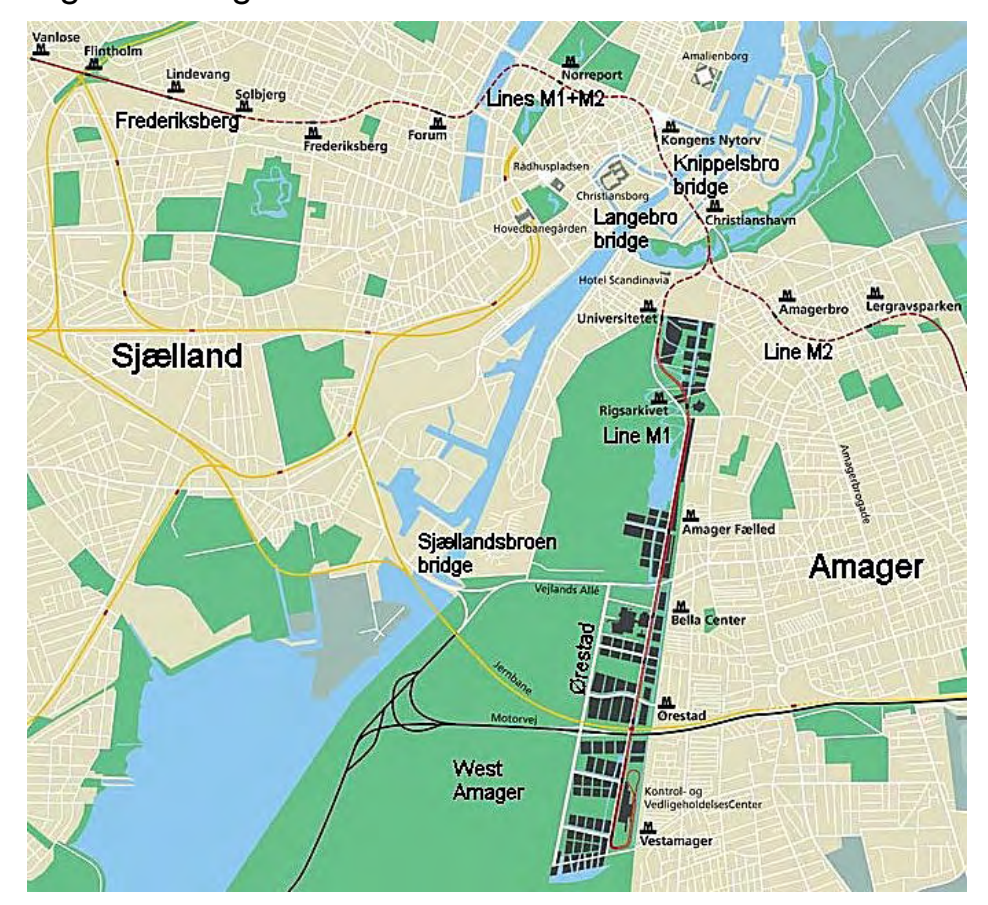

The alignment of the M1 metro line in west Amager largely corresponds to the 1961 plan. The new town Ørestad will expand over the next 20 years to an area of 310 hectare, providing 60,000 jobs, 20,000 education places and 20,000 dwellings. Some larger companies have built new offices in Ørestad: Telia, Copenhagen Energy, Keops and Ferring. The Danish Broadcasting Corporation transferred all its activities to a new television centre in $\varnothing$ restad in 2005. The University of Copenhagen has been enlarged in the area, and the construction of an IT University is finalised.

Phase 2 of the metro opened in two parts: phase 2a, between Nørreport and Frederiksberg, opened in May 2003, while phase 2b, between Frederiksberg and Vanløse opened in October 2003. Both metro lines continued their alignment in this phase from Nørreport to Vanløse. With phase 2 completed, the metro system has a total length of $16 \mathrm{~km}$ and consists of 17 stations, of which eight are underground.

Phase 3, the last projected phase of the Copenhagen Metro, will continue line M2 from Lergravsparken station to Copenhagen's international airport at Kastrup. This phase will open for operation in autumn 2007. The full metro system will be a 22-km network, of which $11 \mathrm{~km}$ will be underground. 
The 2003 Traffic Plan also contains a proposal for phase 4 of the metro, the City Ring, with construction costs amounting to DKK 15 billion (approximately EUR 2.0 billion). Connecting areas close to the city centre, the City Ring will provide good opportunities for interchanging at major metro and S-train stations. Various alignments were proposed. Phase 4 will not be built until 2015 at the earliest.

The Copenhagen Metro is fully automated and operated from a computer centre in Ørestad. The M1 and M2 lines operate with a 4-minute headway between trains during peak periods, which gives a 2-minute headway in the city centre. In the out of peak periods the M1 and M2 lines operate with a 6-minute headway. The operational system allows a minimum headway of only 85 seconds between trains. The metro operates in a self-contained network.

As the metro network has been expanded, changes have been made to the bus service in the capital, including the introduction of a so-called A-line bus network. A-line buses are highfrequency city buses that operate without timetables. They cross the metro network frequently and therefore serve as an access/egress mode to/from the metro.

Two corridors across the Frederiksberg and one, so-called, catchment area were defined in the metro impact study. The corridors were used for conducting traffic counts while the catchment area was used for identification of the respondents in the panel interviews. Figure 2 shows the geographical position of the corridors (the red lines) and the catchment area (the blue circle) where the dashed line shows the alignment of the $\mathrm{M} 1$ and $\mathrm{M} 2$ metro lines. The catchment area has the centre at the Frederiksberg metro station. The impact of the metro's phases $2 \mathrm{a}$ and $2 \mathrm{~b}$ are measured in Frederiksberg.

The second part of the capital where the metro's impact is measured is so called the Harbour corridor, which is the sea channel between the islands of Sjælland and Amager. Figure 2 also shows the Harbour corridor. The corridor is defined by two bridges; the Langebro and Knippelsbro bridges (see Figure 1). The impact of the metro's phases $1,2 \mathrm{a}$ and $2 \mathrm{~b}$ are measured in the Harbour corridor.

Figure 2. Traffic corridors and the catchment area in the project

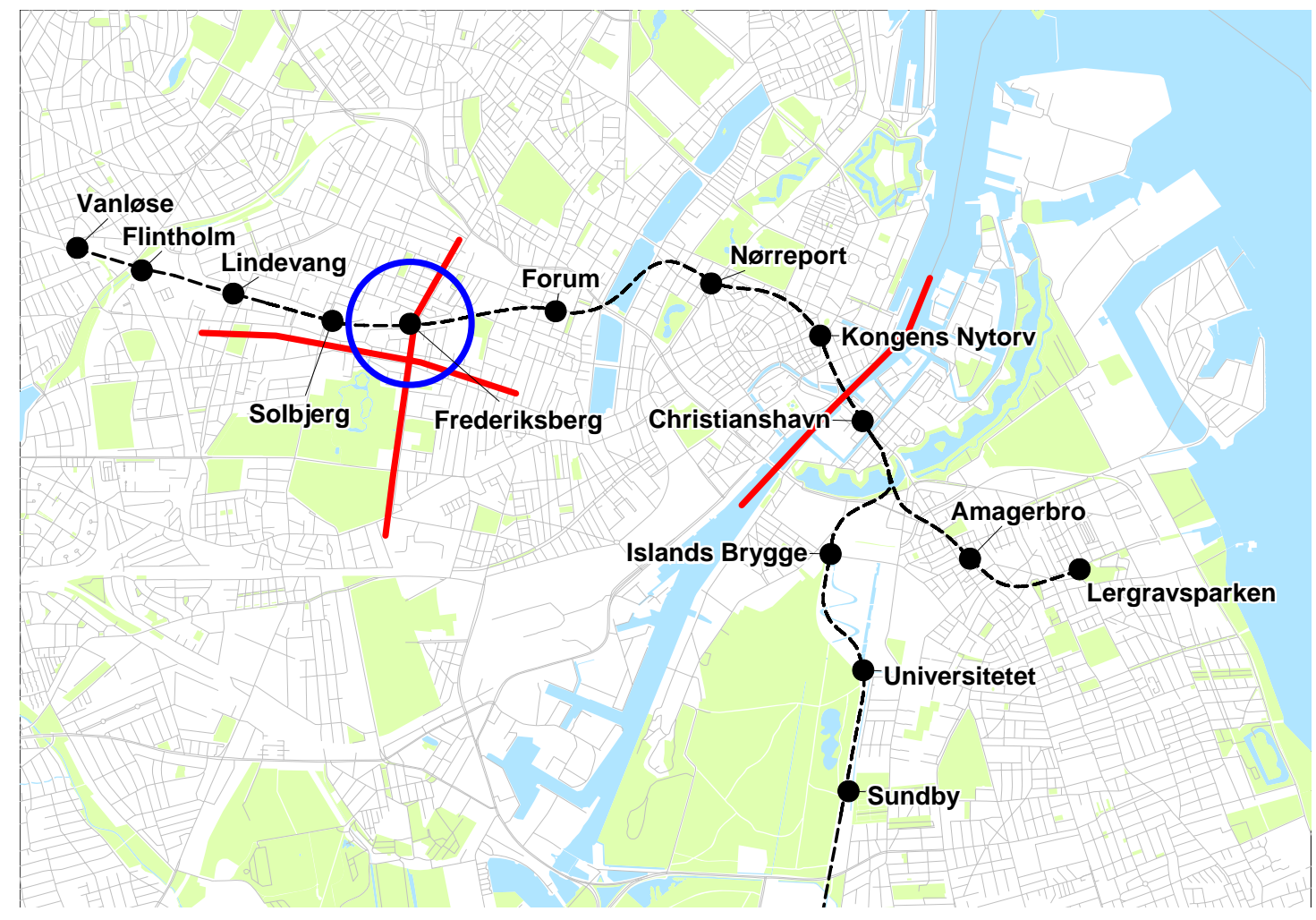




\section{DATA COLLECTION}

Data from different sources were used in the analysis and can be classified into traffic counts, panel data and postcard data. Traffic counts refer to the private car, bus, bicycle and metro modes. Table 1 shows the sources of the traffic counts used in the analysis.

In addition, traffic counts were performed at checkpoints outside the research area to monitor general fluctuations in traffic over time. Copenhagen Municipality and the Danish Road Directorate collected these data for the period 1998-2004.

Panel surveys were conducted as part of the metro impact study in the six-month period before and after the opening of phase 1 (the Harbour corridor) and phase $2 a$ (the area of Frederiksberg). The Harbour corridor sample consisted of 1.000 respondents, recruited by postcard surveys which were completed ahead of the panel surveys. The Frederiksberg sample consisted of 500 respondents, which were recruited randomly from a catchment area defined with a radius of 500 meters around the Frederiksberg metro station. Interviews were conducted by telephone.

Table 1. Description of traffic counts

\begin{tabular}{lccc}
\hline \multicolumn{1}{c}{ Source } & Modes & Time interval & Type of count \\
\hline The Copenhagen metro impact study & Road vehicles & $2001-2004$ & Manual \\
The Copenhagen metro impact study & S-train passengers & $2001-2004$ & Manual \\
Copenhagen Municipality & Road vehicles & $1990-2004$ & Manual/Automatic \\
The Danish Road Directorate & Road vehicles & $1998-2004$ & Automatic \\
The Copenhagen bus company & Bus passengers & $1996-2004$ & Automatic \\
The Danish State Railways & S-train passengers & $1990-2004$ & Manual \\
The Copenhagen metro company & Metro passengers & $2003-2004$ & Manual/Automatic \\
\hline
\end{tabular}

\section{TRANSPORT IMPACTS OF THE METRO}

Table 2 shows development of car traffic on the borders of the Copenhagen and Frederiksberg municipalities (checkpoints) since 1998. The roads selected are major roads from the north, west and south to the city centre. All counts were done automatically and refer to an average workday traffic. We also present the development of the Danish GDP in the table because traffic development is closely related to economic activity. The figures in table 2 show that, with some minor variations, car traffic in general has increased in the Greater Copenhagen area since 1998 as well as the GDP. 
Table 2. Observed car traffic at checkpoints on an average workday and GDP in the period 1998-2004 (index 100 = year 2000)

\begin{tabular}{ccccccc}
\hline Year & Englandsvej & $\begin{array}{c}\text { Roskilde- } \\
\text { vej }\end{array}$ & $\begin{array}{c}\text { Strand- } \\
\text { vejen }\end{array}$ & $\begin{array}{c}\text { Lyngby- } \\
\text { vejen }\end{array}$ & $\begin{array}{c}\text { Amager } \\
\text { motorway }\end{array}$ & GDP \\
\hline 1998 & - & - & 101 & 96 & 89 & 95 \\
1999 & 101 & 98 & 103 & 97 & 94 & 97 \\
2000 & 100 & 100 & 100 & 100 & 100 & 100 \\
2001 & 96 & 104 & 107 & 101 & 100 & 101 \\
2002 & 99 & 101 & 107 & 99 & 104 & 102 \\
2003 & 103 & 102 & 114 & 100 & 108 & 103 \\
2004 & 105 & 102 & 113 & 101 & 112 & 105 \\
\hline
\end{tabular}

Source: Copenhagen Municipality, the Danish Road Directorate and the Danish Statistical Bureau

Table 3 summarises the transport effects of the Copenhagen metro in 2003 and 2004, relative to 2002 (the last year before opening of the metro). The impacts are based on the traffic counts. Data analysis in Frederiksberg shows that between the two corridors only the one crossing the metro alignment (the North-South corridor) was affected by the metro. We refer therefore in the rest of the paper to this corridor where referring to the Frederiksberg area.

The absolute figures, which lie behind the table figures, represent passenger transport (i.e. for each transport mode number of passengers transported is observed) for an average weekday, i.e. Monday to Friday. The rest of the paper explains the obtained impacts.

Table 3. Transport impacts of the Copenhagen metro

\begin{tabular}{lllll}
\hline & & & 2004 \\
\hline & Frederiksberg & Harbour corr. & Frederiksberg & Harbour corr. \\
\hline General growth & $+1 \%$ & $+1 \%$ & $+5 \%$ & $+6 \%$ \\
General growth in the & $+7 \%$ & $+9 \%$ & $+19 \%$ & $+23 \%$ \\
$\begin{array}{l}\text { public transport } \\
\text { General induced traffic }\end{array}$ & $+0 \%$ & $+1 \%$ & $+3 \%$ & $+4 \%$ \\
$\begin{array}{l}\text { Induced traffic in the public } \\
\text { transport }\end{array}$ & $+0 \%$ to $1 \%$ & $+0 \%$ to $+2 \%$ & $+5 \%$ to $+6 \%$ & $+8 \%$ to $+10 \%$ \\
$\begin{array}{l}\text { Induced traffic in the metro } \\
\text { traffic }\end{array}$ & $+0 \%$ to $+6 \%$ & $+1 \%$ to $+3 \%$ & $+15 \%$ to $+18 \%$ & $+15 \%$ to $+18 \%$ \\
\hline $\begin{array}{l}\text { Decrease in car transport } \\
\text { Decrease in bus transport }\end{array}$ & $-7 \%$ to $-8 \%$ & $-3 \%$ to $-4 \%$ & $-12 \%$ to $-13 \%$ & $-4 \%$ to $-5 \%$ \\
$\begin{array}{l}\text { Decrease in S-train } \\
\text { transport }\end{array}$ & $0 \%$ to $-2 \%$ & - & $-21 \%$ to $-26 \%$ & $-43 \%$ to $-47 \%$ \\
$\begin{array}{l}\text { Decrease in bicycle } \\
\text { transport }\end{array}$ & $0 \%$ to $-4 \%$ & $0 \%$ to $-4 \%$ & $0 \%$ to $-9 \%$ & - \\
\hline
\end{tabular}




\subsection{Traffic growth}

The analysis of the traffic counts in the Frederiksberg and Harbour corridors for the period 1990-2002 shows an average annual total growth (i.e. all travel modes) of approximately 0,5$1 \%$. The observed growth 2002-2003 was $1 \%$, which means that in the first year of the metro operation (phase 1) the metro did not generate any traffic that cannot be explained by ordinary economic figures such as increase in GDP. The general traffic growth in 2004 relative to 2002 was $5-6 \%$, which is higher than expected in the case the metro was not built. This is to say that the metro has succeeded in generating new traffic across the two corridors, either in the form of induced traffic or changes in the destination choice.

The historical tendency of the public transport development across the two corridors up to 2003 was negative. In 2003 the general growth in the public transport was turned to be positive, in the range between $7-9 \%$. Therefore, even though both the bus and S-train traffic decreased from 2002 to 2003, the metro succeeded in lifting up the total public transport in the two corridors in 2003 . This is partially explained by the modal shift (from non public transport modes to the metro) and partially due to the existence of induced traffic. The general growth in the public transport accelerated to $19-23 \%$ in 2004 relative to 2002 due to three factors: a) the metro network expanded in 2003 , where both phase $2 \mathrm{a}$ and $2 \mathrm{~b}$ opened, b) the reliability of the metro was improved dramatically in 2004 relative to 2003 and c) adaptation of the metro, as a new travel model, reached much further in the traveller's conscious in 2004.

\subsection{Induced traffic}

By induced traffic we mean the traffic that occurs due to the infrastructural improvements. In the first year of operation no general induced traffic occurred in the two corridors. In 2004 the general induced traffic was in a range $3-4 \%$, which is to be expected due to the metro's enlargement in 2003 (opening of phases $2 a$ and $2 b$ ).

Accordingly, the public transport induced traffic was negligible in 2003, while in 2004 it reached $6 \%$ in Frederiksberg and $10 \%$ in the Harbour corridor. Finally, the metro's induced traffic was rather small in $2003(3-6 \%)$, while quite substantial part of the total metro traffic in 2004, where the induced traffic part was between $15-18 \%$ in both corridors.

There are two main reasons for the observed induced traffic in the corridors. The first reason is that travellers across the two corridors travel more in 2003/04 than in 2002 (increase in trip rate), and the second is changes in the destination choice.

The panel surveys in the Frederiksberg area and the Harbour corridor confirm that the trip rate in the after-panels is higher than the trip-rate in the before-panels. The analysis of the panel data in Frederiksberg shows a very clear picture: a) the trip rate rose from 3,17 trips per person per day in the before-panel to 3,65 trips per person per day in the after-panel, and b) the trip rate for bicycle rose by $10 \%$, the trip rate for car rose by $16 \%$, while the public transport trip rate rose by $40 \%$ from before-survey to after-survey. The analysis of the Harbour corridor panel shows weaker tendencies than in Frederiksberg: a) the trip rate rose from 3,26 trips per person per day in the before-panel to 3,30 trips per person per day in the after-panel, and b) the trip rate for bicycle decreased by $15 \%$, the trip rate for car rose by $6 \%$, while the public transport trip rate rose by $33 \%$ from before-survey to after-survey.

The further analysis of the panel data shows that the induced traffic occurs predominantly in respect to leisure activities, such as shopping, visiting friends/family and cultural/sport activities.

\subsection{Modal changes}

Modal changes are presented in table 3 in intervals rather than as point values. One side of the interval represents the observed changes from 2002 to 2003/04, while the other side of the interval represent the changes between the extrapolated traffic in 2003/04 (i.e. the expected traffic in 2003/04 in the case the metro was not existed) and the observed 2003/04 
traffic. So, while the first value of the interval refers to the observed modal effect, the second value in the interval refers to the expected modal effect.

\section{Car traffic}

The car traffic (presented in number of persons travelled by car) decreased by $3-4 \%$ in 2003 relative to 2002 in the Harbour corridor, while the car traffic decrease was $7-8 \%$ in the Frederiksberg corridor. The main reason for that is differences in population density, where Frederiksberg is more densely populated than area around the Harbour corridor. Higher population density in Frederiksberg gives possibilities for both short and long car trips to be shifted to the metro.

The tendency of car shift to the metro continued in 2004, where modal shift in the Harbour corridor was $4-5 \%$ relative to 2002 while in the Frederiksberg, the car shift was $12-13 \%$. Again, larger population in Frederiksberg is the main reason for differences in car shift between the two areas.

\section{Bus traffic}

According to the literature, new infrastructures affect bus traffic in particular, e.g. about $50 \%$ of the Athens metro passengers are former bus users (Golias, 2002) while about $70 \%$ of Croydon Tramlink passengers are former bus users (Copley at al., 2002).

The bus traffic decreased from 2002 to 2003 in Frederiksberg by 18-21\%, while the corresponding decrease in the Harbour corridor was $39-40 \%$. There are two reasons why the bus decrease was larger in the Harbour corridor than in Frederiksberg. The first one is that the Copenhagen bus authority (HUR) made changes in the bus service from 2002 to 2003 in order to accommodate for metro introduction, which were much more radical in the Harbour corridor area. Secondly, the area of Frederiksberg has a large portion of elderly people. They do not feel safe neither in metro, which is run automatically at the computer centre in Ørestad, nor at the Frederiksberg metro station, which is an underground station. In conclusion, the elderly bus travellers in Frederiksberg were reluctant to shift to the metro in 2003, and they rather stayed being bus passengers.

The tendency of bus transport shift to the metro observed in 2003 continued in 2004 . The decrease in 2004 relative to 2002 was $21-26 \%$ in Frederiksberg and $43-47 \%$ in the Harbour corridor. The observed changes in 2003 and 2004 show that the biggest part of those bus travellers who actually shifted to the metro did that already in 2003.

\section{S-train traffic}

There is about $200 \mathrm{~km}$ of S-train track in Copenhagen, which is a very well functional city railway network. The S-train does not cross the Harbour corridor (this system does not operate on the island of Amager), which means that the modal shift from S-train to metro has been measured in the study only in Frederiksberg.

In 2003, the metro alignment crossed the existing S-train network only at the station of Nørreport, which is though the busiest train station in the whole country. A moderate maximum of $2 \%$ of S-train passengers on the Frederiksberg corridor shifted to metro in 2003.

In 2004, the metro alignment crossed the S-train network at three stations, i.e. Nørreport, Flintholm and Vanløse, where the last two stations were reached with opening of the metro phases $2 \mathrm{a}$ and $2 \mathrm{~b}$. In $2004,18-20 \%$ of the 2002 S-train passengers on the Frederiksberg corridor shifted to metro. The reason for this rather large shift is that by changing to metro at Vanløse/Flintholm stations for those travelling to the city centre it is possible to obtain a significant gain in travel time, especially if the destination is a part of the city covered only by metro, e.g. Frederiksberg, Christianshavn and Kongens Nytorv. 


\section{Bicycle traffic}

Bicycle traffic is rather substantial in the whole country and especially in Copenhagen, e.g. there were approximately 40.000 bike trips over the Harbour corridor in an average weekday in 2004 and that is 4.000 trips more than by bus and 8.000 trips less than by metro.

Bicycle counts in Copenhagen are rather unreliable. First of all, it is rather difficult to count bikers in rush hours. Secondly, most counts are done only once a year, e.g. TuesdayThursday in March or September, in a period between 6 a.m. and 6 p.m.. Depending on the weather conditions the bike traffic can vary substantially at the counting day, which is difficult to correct for when calculating for an average annual weekday.

For the reasons above, we have developed a methodology for calculating the modal shift from bicycle to metro based on the combination of traffic counts and panel data. The methodology is common for both areas in the project. According to the applied method up to $4 \%$ of the bikers shifted to metro in 2003 , while in 2004 up to $9 \%$ of the bikers in the two corridors shifted to metro.

\subsection{Changes in choice of time of day}

Figure 3 shows the number of passenger trips by public transport across five time periods of the day, i.e. morning, morning peak, day, afternoon peak, evening, in 2002, 2003 and 2004 on the Frederiksberg corridor. According to the figure, the number of trips made by public transport in the afternoon and evening period rose with the introduction of metro. Actually, the more metro the more obvious this tendency is, i.e. the effect is larger in 2004 than in 2003.

According to the existing literature regarding activity based modelling the travellers tend to combine their activities in the afternoon/evening period, e.g. increase in leisure activities. According to figure 3 it seems that the traveller's mobility has increased after the introduction of metro.

Figure 3. Changes in public transport in Frederiksberg in 2002, 2003 and 2004 across five time periods

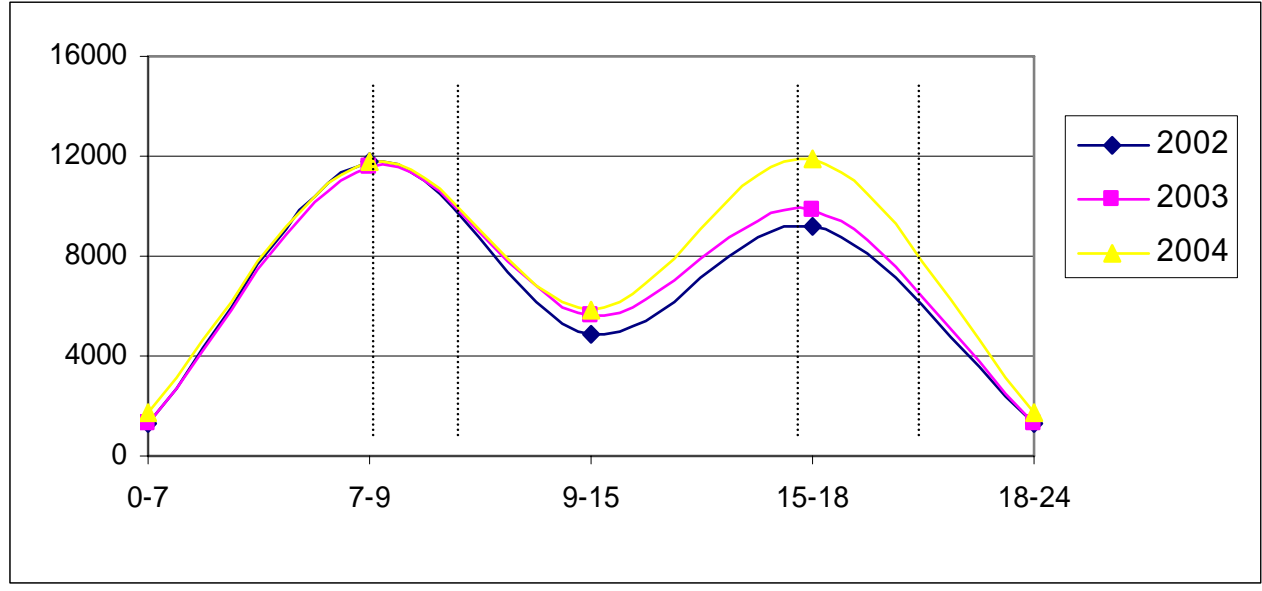

\subsection{Changes in destination choice}

The postcard analysis in Frederiksberg has shown that approximately $40 \%$ of the public transport leisure trips across the corridor in 2002 ended in the neighbouring city parts to Frederiksberg. In 2003 this share decreased to only 17\%, while the destinations along the metro's alignment rose sharply (e.g. city centre and Christianshavn). 
This change indicates that for leisure activities, such as shopping, travellers are prepared to travel longer in distance (which does not necessarily mean also longer in travel time) in order to reach more attractive destinations as a result of better accessibility. The panel survey in the Frederiksberg area show that while the average trip length is constant between the before panel and after panel, the average trip time has fallen.

\section{CONCLUSIONS}

Analysis of the traffic counts, postcard data and panel data in the project for a period 1990 to 2004 shows that the introduction of metro in October 2002 (phase 1) and 2003 (phases 2a and $2 \mathrm{~b}$ ) changed travel patterns in the capital dramatically. This is related to both the number of impacts but also their magnitude.

It is interesting to observe that while the changes in traffic growth and induced traffic are rather similar in the two areas, the modal changes are different in magnitudes in the two areas, e.g. while decrease in car traffic is approximately twice as big in Frederiksberg than across the Harbour corridor the opposite is true for the shift of the bus travellers. The main reason for this effect is that general (macro) effects, such as general traffic growth, are indifferent to the population density, while the micro effects, such as shift of bus passengers to metro, are in function of the population density. Other reasons for this effect are the existing level of service, age/income structure of the population and the initial modal split in the areas.

Already in 2007 the metro network will be enlarged by opening of the third phase, where metro line M2 will continue its alignment towards the International Airport Kastrup. By 2015 the metro's phase 4, the so called Metro City Ring, will be opened. It can be therefore expected that the transport impacts presented in the paper will continue in future.

First, both the traffic growth and induced traffic will continue to increase in future as the travellers will continue to change their behaviour according to infrastructural changes. It is though expected that in future apart of increase in leisure trips the commuting trips will increase also because some travellers will choose place of dwelling/work close to the metro's alignment, i.e. the effect of destination choice.

Second, with the increase of the metro network we expect that peak periods will change. Especially the afternoon peak will increase and continue in the evening hours due to increased mobility. Opening of the electronic ticket for public transport by 2007 will enhance this effect.

Third, the bus traffic has already been influenced strongly by the metro. However, the decrease of the bus traffic in the densely populated areas (e.g. Frederiksberg) was smaller than expected. There is therefore a potential for shifting more bus travellers to the metro in these areas. More generally though we can assume that with a more reliable metro service there will be more of the 2002 bus passengers who will shift to the metro.

Finally, the future shift from car to metro is not only in function of the metro's enlargement but also of the traffic policies to be introduced in the future. These policies include parking policy, public transport ticket pricing and potentially introduction of road pricing. 


\section{References}

Copley, G., Thomas, M. and Georgeson, N. (2002). Croydon Tramlink impact study. European Transport Research Conference. September 9-11. Cambridge, UK.

Golias, J.C. (2002). Analysis of traffic corridor impacts from the introduction of the new Athens Metro system. Journal of Transport Geography. Volume 10, Issue 2, June 2002. Pages 91-97.

Greater Copenhagen Authority (2004). Traffic Plan 2003. Report nr. 87-7971-110-3.

\section{Denmark.}

Rasmussen, S. E. (2001). Steen Eiler Rasmussens København: Et bysamfunds særpræg og udvikling gennem tiderne. Gads Forlag. Copenhagen, Denmark.

Vuk, Goran (2005). Transport impacts of the Copenhagen Metro, Journal of Transport Geography, 13 (2005) pp. 223-233.

Vuk, Goran and Ildensborg-Hansen, Jane (2006). Trafikale effekter af metroen; en før- og efteranalyse. Report 2, Danish Transport Research Institute. 